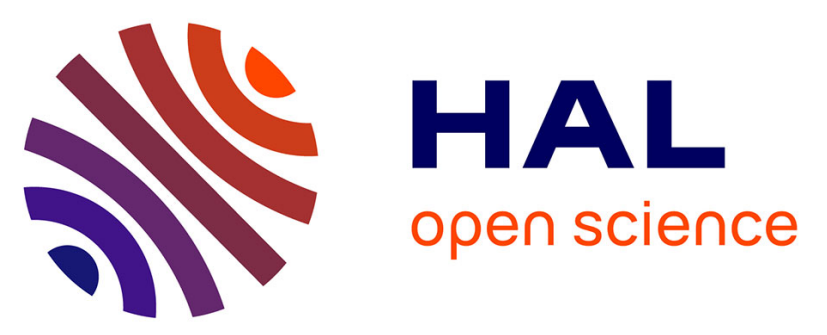

\title{
Impact of MLH1 expression on tumor evolution after curative surgical tumor resection in a murine orthotopic xenograft model for human MSI colon cancer
}

Katy Meunier, Marianne Ferron, Claire Calmel, Jean-François Fléjou, Marc Pocard, Françoise Praz

\section{To cite this version:}

Katy Meunier, Marianne Ferron, Claire Calmel, Jean-François Fléjou, Marc Pocard, et al.. Impact of MLH1 expression on tumor evolution after curative surgical tumor resection in a murine orthotopic xenograft model for human MSI colon cancer. Genes, Chromosomes \& Cancer, 2017, 10.1002/gcc.22472 . hal-01548232

\section{HAL Id: hal-01548232 \\ https://hal.sorbonne-universite.fr/hal-01548232}

Submitted on 27 Jun 2017

HAL is a multi-disciplinary open access archive for the deposit and dissemination of scientific research documents, whether they are published or not. The documents may come from teaching and research institutions in France or abroad, or from public or private research centers.
L'archive ouverte pluridisciplinaire HAL, est destinée au dépôt et à la diffusion de documents scientifiques de niveau recherche, publiés ou non, émanant des établissements d'enseignement et de recherche français ou étrangers, des laboratoires publics ou privés. 
Impact of MLH1 expression on tumour evolution after curative surgical tumour resection in a murine orthotopic xenograft model for human MSI colon cancer

Katy Meunier ${ }^{1}$, Marianne Ferron ${ }^{1}$, Claire Calmel ${ }^{1}$, Jean-François Fléjou ${ }^{1,2}$, Marc Pocard ${ }^{3-5,}{ }^{\dagger *}$ and Françoise Praz ${ }^{1, \dagger}$.

${ }^{1}$ Sorbonne Universités, UPMC Univ Paris 06, INSERM, CNRS, Centre de Recherche SaintAntoine (CRSA), Paris, France

${ }^{2}$ Assistance Publique - Hôpitaux de Paris, Hôpital Saint-Antoine, Service d'Anatomie Pathologique, Paris, France

${ }^{3}$ Assistance Publique - Hôpitaux de Paris, Hôpital Lariboisière, Digestive and Oncology Surgery Department, Paris, France

${ }^{4}$ Paris Diderot University, USPC, Sorbonne Paris Cité, Paris, France

${ }^{5}$ INSERM UMR 965, Angiogenesis and Translational Research Department, Hôpital Lariboisière, Paris, France.

Correspondence :

Françoise Praz, Centre de Recherche Saint-Antoine, 184 rue du Faubourg Saint-Antoine, 75571 Paris cedex 12. E-mail: francoise.praz@upmc.fr or

Marc Pocard, Département Médico-Chirurgical de Pathologie Digestive, Hôpital Lariboisière, 2 rue Ambroise Paré, 75475 Paris cedex 10. E-mail: marc.pocard@gmail.com

†These authors contributed equally to this work.

Funding information. The authors thank the Fondation ARC pour la Recherche sur le Cancer for financial support to KM and a grant to MP (\#3395).

Abbreviated title: MLH1 impact on tumour fate after surgery 


\section{Abstract}

Colorectal cancers (CRCs) displaying microsatellite instability (MSI) most often result from MLH1 deficiency. The aim of this study was to assess the impact of MLH1 expression per se on tumour evolution after curative surgical resection using a xenograft tumour model. Transplantable tumours established with the human MLH1-deficient HCT116 cell line and its MLH1-complemented isogenic clone, mlh1-3, were implanted onto the caecum of NOD/SCID mice. Curative surgical resection was performed at day 10 in half of the animals. The HCT116-derived tumours were more voluminous compared to the mlh1-3 ones $(P=.001)$. Lymph node metastases and peritoneal carcinomatosis occurred significantly more often in the group of mice grafted with HCT116 $(P=.007$ and $P=.035$, respectively). Mlh1-3-grafted mice did not develop peritoneal carcinomatosis or liver metastasis. After surgical resection, lymph node metastases only arose in the group of mice implanted with HCT116 and the rate of cure was significantly lower than in the mlh1-3 group $(P=.047)$. The murine orthotopic xenograft model based on isogenic human $\mathrm{CRC}$ cell lines allowed us to reveal the impact of MLH1 expression on tumour evolution in mice who underwent curative surgical resection and in mice whose tumour was left in situ. Our data indicate that the behaviour of MLH1-deficient CRC is not only governed by mutations arising in genes harbouring microsatellite repeated sequences, but also from their defect in MLH1 per se. 


\section{INTRODUCTION}

Colorectal carcinoma $(\mathrm{CRC})$ is the third most common type of cancer and the second leading cause of cancer-related death. ${ }^{1}$ Approximately one-fourth of patients can be cured by surgery alone, whereas the remaining need to be treated with chemotherapy due to metastasis at the time of diagnosis, development of metastasis or recurrence of disease. The development of CRC involves at least three partially overlapping oncogenic pathways displaying characteristic genetic or epigenetic alterations: microsatellite instability (MSI), CpG island methylator phenotype, and chromosome instability. ${ }^{2-4}$ MSI CRCs represent about $15 \%$ of all CRC and arise due to mismatch repair (MMR) deficiency, either as a result of inherited mutations in one of the MMR genes, most often $M S H 2$ or $M L H 1$, or, more often, through somatic epigenetic methylation of the MLH1 promoter. $^{3,5,6}$ Patients with MSI CRC have a better stage-adjusted prognosis than those with $\mathrm{CRC}$ displaying chromosome instability, ${ }^{7,8}$ and there is increasing evidence showing that MSI influences the response to chemotherapy, ${ }^{3,9-15}$ to ionizing radiation, ${ }^{16}$ and to immunotherapy..$^{17,18}$

It is widely accepted that MMR deficiency is not a transforming event per se, but that it promotes oncogenesis through accumulation of mutations arising during replication as they are left uncorrected due to MMR deficiency. ${ }^{19,20}$ Simple sequence repeats, also known as microsatellites, are particularly prone to insertion and deletion mutations resulting from polymerase slippage. Several genes involved in the control of cell proliferation and differentiation, and DNA damage signalling and repair carry a mononucleotide repeat, ${ }^{21,22}$ which is mutated in MSI CRC at a frequency higher than expected from their length, suggesting that their inactivation may participate in tumour initiation and/or progression. ${ }^{23,24}$ In addition to the numerous MSI-driven mutations inactivating target genes that may be considered as putative novel oncogenes, ${ }^{25} \mathrm{MLH} 1$ deficiency itself may further contribute to tumour progression owing to its role in recombination ${ }^{26,27}$ and apoptosis. ${ }^{28-31}$

Metastasis is a multistep process that requires the ability of tumour cells to invade the underlying tissues, survive in the circulation and colonize various organs, mostly lymph 
nodes, liver and lung in the case of CRC. Most of the mutations found in CRC metastases are present in the paired primary lesion, suggesting that dissemination is an early event during cancer development. ${ }^{32}$ Hence, the potential for metastatic development of CRC possibly relies on intrinsic properties of the primary tumour. ${ }^{32}$

Orthotopic CRC xenograft mouse models have been established by transplanting human colon cancers onto the caecum of deficient mice. ${ }^{33-36}$ Orthotopic xenografts are clinically more relevant than subcutaneous tumours as they may give rise to local or distant metastasis formation, in lymph nodes, in the peritoneum (carcinomatosis), or in the liver. ${ }^{34,36-}$

${ }^{41}$ Furthermore, orthotopic xenografts are valuable models to evaluate tumour progression after curative surgical tumour resection since they represent the possible fate of tumours arising in humans, i.e. cure (when there is no evidence of disease), local recurrence or distant metastases. ${ }^{39,40}$ As an example, we previously reported that specific alterations of Ecadherin expression or TP53 in LoVo, an MSI colon cancer cell line, dramatically changed the rate of cure and metastatic behaviour after surgical resection of the tumour. ${ }^{39}$

The purpose of the present study was to investigate whether $M L H 1$ expression per se had an impact on the evolution of the tumour after curative surgical resection or when left in situ, using a murine orthotopic xenograft model based on the MLH1-deficient HCT116 cell line and an isogenic MLH1-complemented clone.

\section{MATERIALS AND METHODS}

\section{Cell lines}

Experiments were performed on the MLH1-deficient colorectal cancer cell line HCT116, kindly provided by Peter Karran in june 1995 (Imperial Cancer Research Fund, Clare Hall, United Kingdom), and its $M L H 1$-complemented counterpart cell line mlh1-3, obtained by transfecting the HCT116 cell line with an expression vector containing the wild-type $M L H 1$ cDNA, as described. ${ }^{42}$ Cells were regularly authenticated using the short tandem repeat 
(STR) panel recommended by the International Cell Line Authentication Committee, as described in detail below. In particular, cells were typed at the beginning and at the end of the experimental procedures; the genotypes of the parental HCT116 and its MLH1complemented counterpart cell line are shown in Supporting Information Table 1. Compared with the HCT116 genotype published by the American Type Cell Culture (ATCC), there are 2 minor differences, consisting of the addition of $1 \mathrm{bp}$ at the longer vWA allele (22.1 instead of 22) and the partial (in HCT116) or complete (in mlh1-3) loss of the chromosome Y-specific amelogenin allele. As discussed in the Results section, such differences do not challenge the identity of the HCT116 cells used in this study, but rather underline that novel indel mutations are highly susceptible to arise during replication of the mismatch repair-deficient HCT116 cells. Cells were grown in monolayer cultures in DMEM (Dulbecco's Modified Eagle's Medium, Sigma, France), supplemented with $10 \%$ of heat-inactivated foetal bovine serum, Lglutamine $(2 \mathrm{mM})$, penicillin $(100 \mu \mathrm{g} / \mathrm{mL})$, and streptomycin $(100 \mathrm{Ul} / \mathrm{mL})$, in a humidified incubator at $5 \% \mathrm{CO}_{2}$. The mlh1-3 cell line was maintained under selective pressure by adding $100 \mu \mathrm{g} / \mathrm{mL}$ hygromycin, until injection into mice.

\section{Genomic DNA extraction and STR fingerprinting}

The DNeasy tissue kit (Qiagen, Hilden, Germany) was used to extract genomic DNA from cell pellets, according to the manufacturer's instructions. STR genotypes were established using eight highly polymorphic tetranucleotide STR markers (D5S818, D7S820, D13S317, D16S539, CSF1PO, THO1, TPOX, and VWA) and the Amelogenin marker that discriminates the $\mathrm{X}$ from the $\mathrm{Y}$ chromosome due to a 6 -bp insertion. PCR were carried out using $0.2 \mathrm{mM}$ dNTP, $0.15 \mathrm{mM}$ primers (0.2 mM for D7S820), 0.5U KAPA2G Robust HotStartTaq polymerase (Kapa Biosystems, Wilmington, MA), and sense primers labeled with 6-FAM or HEX. After a $3-$ min step at $95^{\circ} \mathrm{C}, 35$ cycles of $15 \mathrm{sec}$ at $95^{\circ} \mathrm{C}, 15 \mathrm{sec}$ at $55^{\circ} \mathrm{C}$ and $15 \mathrm{sec}$ at $72^{\circ} \mathrm{C}$, followed by a $1 \mathrm{~min}$ final extension at $72^{\circ} \mathrm{C}$ were performed. PCR products were diluted in formamide containing ROX-labelled 400 HD size markers (PE Applied Biosystems, Foster City, CA) and electrophoresed in $36-\mathrm{cm}$ capillaries containing POP-7 on an ABI 
PRISM® 3130 Genetic Analyzer (PE Applied Biosystems). The apparent sizes of the alleles were determined using the GeneMapper Analysis software (PE Applied Biosystems).

\section{MSI analysis}

MSI was investigated using four highly polymorphic CAn dinucleotide microsatellite markers located on three different chromosome arms (5q, 17p, and 18q). PCR was carried out in $20 \mu \mathrm{L}$ using $0.2 \mathrm{mM}$ dNTP, $0.5 \mathrm{U}$ HotStarTaq polymerase (Qiagen), and sense primers labelled with 6-FAM (D5S107), HEX (D18S474) or NED (D17S1791, D18S1127). The primer sequences are from the Ensembl Genome System website. After a 15 -min step at $95^{\circ} \mathrm{C}, 35$ cycles of $30 \mathrm{sec}$ at $94^{\circ} \mathrm{C}, 30 \mathrm{sec}$ at $55^{\circ} \mathrm{C}$ and $30 \mathrm{sec}$ at $72^{\circ} \mathrm{C}$, followed by a 6 min final extension at $72^{\circ} \mathrm{C}$, were performed. PCR products were analysed as described above for STR fingerprinting.

\section{Detection of frameshift mutations}

The regions encompassing the repeated mononucleotide sequences contained in 26 selected genes (Table 1) were amplified either in monoplex or in multiplex PCR, as previously described. ${ }^{23}$ Oligonucleotide sequences and protocol details are available upon request. The electrophoresis profiles of the PCR products obtained with mlh1-3 were compared to the HCT116 reference profiles.

\section{MLH1 protein expression}

MLH1 protein expression in HCT116 and mlh1-3 cell lines was detected by Western blot using a rabbit polyclonal antibody raised against $\mathrm{MLH} 1$ (PC56, $1 \mu \mathrm{g} / \mathrm{mL}$, Oncogene Research Products, Cambridge, MA) followed by subsequent incubation with sheep antirabbit antibodies conjugated with horseradish peroxidase (Amersham Pharmacia Biotech, Uppsala, Sweden). Analysis of tumour tissues obtained from mice was performed by immunohistochemistry on 4- $\mu$ m slides incubated with an MLH1-specific mouse monoclonal antibody (dilution 1:400, clone G168-728, BD Biosciences, East Rutherford, NJ) after antigen retrieval with buffer, $\mathrm{pH}$ 6.0. 


\section{Animal experiments}

Locally bred female NOD/SCID mice of 6-8 weeks of age were used for implantation. The animals were maintained under specific pathogen-free conditions, and food and water were supplied ad libitum. Housing and all procedures involving animals were conducted in accordance with the European Communities Council Directive (2010/63/UE) for the care and use of animals for experimental procedures and complied with the regulations of the French Ethics Committee in Animal Experiment "Charles Darwin" registered at the "Comite National de Réflexion Ethique sur l'Expérimentation Animale" (lle-de-France, Paris, no5). Pr Marc Pocard supervised all experiments (agreement no. 75-1229 approved by the "Direction Départementale de la Protection des Populations", Paris, France). All efforts have been made to protect mice from pain, suffering, injury and disease.

\section{Tumour models}

Subcutaneous tumours were established by injecting $5 \times 10^{6}$ cells into the flank of 5 mice per cell line. When subcutaneous tumours were exponentially growing, mice were sacrificed to remove the tumours, which were then cut into fragments. The tumour fragments were subsequently implanted subcutaneously into the lateral flank of 5 other mice under inhaled anaesthesia and the incision was closed with a metal wound clip. When tumours reached a sufficient volume, they were resected and cut in $2 \times 2 \times 2 \mathrm{~mm}$ fragments for further intracaecal grafts.

\section{Transplantation procedure}

For each cell line, 30 mice were anaesthetized by intraperitoneal injection of $0.2 \mathrm{~mL}$ solution of ketamine (100 mg/kg body weight, Ketalar, Parapharm, Chinon, France) and xylazine (40 $\mathrm{mg} / \mathrm{kg}$ body weight, Rompun, Bayer, La Garenne-Colombes, France). The abdomen was prepared for sterile surgery, as previously described. ${ }^{36} \mathrm{~A}$ median incision was performed to exteriorize the colon. A $2 \times 2 \times 2 \mathrm{~mm}$ fragment of solid tumour was then deposited at the surface of the serous membrane of the caecum, fixed with a thread (vicryl $7 / 0$, Ethicon, 
France) and covered with $0.5 \mathrm{~mL}$ of biological glue (Beriplast, Aventis, Gentilly, France). The caecum was finally replaced in the abdominal cavity and the abdominal wall was closed in two layers: the aponevrose with thread (prolene 5/0, Ethicon, Issy-les-Moulineaux, France) and the skin with a metal wound clip. The group of 30 mice transplanted with either HCT116 or mlh1-3 cells were randomly divided into 2 groups of 15 mice: one in which the tumours were left in situ to evaluate the natural tumour history and one that underwent surgical resection; mice were caught randomly and were assigned alternately to each group.

\section{Surgical resection}

Surgical resection was performed 10 days after orthotopic transplantation. Mice were anesthetized, abdomen was prepared for sterile surgery and a median incision was made, using the above-described protocol. The colon was exposed after careful dissection and haemostasis of peritoneal adhesions. The caecum was completely resected using a surgical clip, as described. ${ }^{35,36}$ The clip was covered for final haemostasis and asepsis with $0.5 \mathrm{~mL}$ of biological glue. The bowel was replaced in the abdominal cavity and the wall was closed in two layers.

\section{Tumour growth and metastasis evaluation}

For each animal, an autopsy was performed at day 45 after tumour implantation. Tumour volumes were calculated using the formula $V=a \times b^{2} / 2$, where $a$ is the length of the tumour (largest diameter) and $\mathrm{b}$ is the perpendicular width of the tumour (smallest diameter), both measured with a calliper. For each animal, local recurrence and distant metastases (lymph node, liver and lung metastases, peritoneal carcinomatosis) were searched macroscopically at autopsy with histologic confirmation and immunohistochemical labelling of MLH1, as described above. The animals were considered cured if no tumour could be detected in any of the above-mentioned organs when inspected at autopsy. 


\section{Statistical analyses}

On the basis of a unilateral alpha type one error of $5 \%$, it was necessary to include 10 mice per group to achieve a $90 \%$ statistical power if the expected event ratio (local or distant recurrence) was 4 , and 8 mice per group if the mean tumour volume ratio was expected to decrease 4-fold upon expression of MLH1. Two-sided Fisher's exact test was used to compare the proportion of mice with recurrence, lymph node metastases, peritoneal carcinomatosis and liver metastases. Tumour volumes were compared using a one-tailed Mann-Whitney $U$ test. Analyses were performed using the Prism 5 software (GraphPad Software Inc, La Jolla, CA).

\section{RESULTS}

\section{Feasibility of orthotopic intracaecal xenografts and tumour resection}

Among the $60 \mathrm{NOD} / \mathrm{SCID}$ mice that had been grafted on the caecum, one died during surgery, one the following day and one at day 8 (1/30 and 2/30 for HCT116 and mlh1-3, respectively), giving a 5\% graft-related mortality. Among the 27 animals that did not undergo surgery, tumour graft implantation was successful in 21 animals (10/14 and 11/13, for HCT116 and mlh1-3, respectively), giving an overall tumour take rate of $78 \%$. Among the 30 animals that underwent surgical resection at day 10 , five of them (16\%) died during the first 8 days after surgical tumour resection (2/15 and 3/15 for HCT116-R and mlh1-3-R, respectively), with one dying the next day.

Microscopy of haematoxylin-eosin (HE) sections showed that macroscopic tumours from both HCT116 and mlh1-3 exhibited invasive growth in the murine caecum towards the intestinal lumen (Figure 1A and $\mathrm{B}$ ); both HCT116 and mlh1-3 tumours were able to grow through the serosa and invade the muscular layer and the mucosa. Visual examination at autopsy and microscopic examination of HE-stained sections showed that tumours also gave 
rise to lymph node metastases (Figure $1 \mathrm{C}$ and $\mathrm{D}$ ), liver metastases in one case (Figure 1E and $F$ ), and peritoneal carcinomatosis (Figure $1 \mathrm{G}$ and $\mathrm{H}$ ). HCT116-derived tumours cells were more frequently poorly differentiated, with increased necrosis, than mlh1-3; in addition, HCT116 cells were smaller and less cohesive.

\section{Molecular characteristics of the HCT116 and mlh1-3 cell lines and their counterpart tumours}

The expression of MLH1 was investigated in the cell lines and their derived tumours by Western blot and immunohistochemical staining with an anti-MLH1 antibody (Figure 2A-C). As expected, the expression of MLH1 was undetectable in the HCT116 cell line and in the derived HCT116 tumour tissue (Figure 2A and B). In the mlh1-3 cell line obtained by transfecting the MLH1-deficient HCT116 cell line with a wild type MLH1-expressing vector, MLH1 was expressed at normal control levels (Figure 2A) and sustained throughout the course of the experiments (not shown). MLH1 expression in grafted mlh1-3 tumours was maintained in spite of discontinued antibiotic selection pressure for the in vivo experiments (Figure 2C). Interestingly, HE staining showed that tumours derived from HCT116 or mlh1-3 cells displayed similar morphological features (Figure $2 \mathrm{~B}$ and $\mathrm{C}$ ). Figure 2 shows the MSI phenotype of the HCT116 and mlh1-3 cell lines, as well as their corresponding tumour tissues, determined using 3 highly polymorphic dinucleotide microsatellite markers. As expected, the HCT116 cell line (Figure 2D) displayed a typical high MSI profile, with numerous peaks corresponding to the amplification of alleles derived through deletion or insertion of CA motifs in the parental alleles. Conversely, no microsatellite instability could be detected in the mlh1-3 cell line (Figure 2E), or its derived subcutaneous (Figure 2F) or intracaecal (Figure 2G) tumour tissues obtained from the 23 mice analysed at autopsy (Figure 2 and data not shown).

We further compared the mutational status of 26 genes harbouring a mononucleotide repeat in HCT116 and mlh1-3 cells (Table 1). No difference was found between the two cell lines: the coding repeated sequences were wild-type in sixteen genes, while seven genes 
displayed a monoallelic 1 bp deletion (BAX, MBD4, POLD3, RAD50, RECQL, TOPBP1 and TOPORS) together with a wild-type allele; the other three genes had 1- or 2-bp biallelic deletions (MRE11, MSH3 and TGFBR2) (Table 1).

DNA fingerprinting of the two cell lines and their derived intracaecal tumours was performed using 8 STR markers that enables a 1 in $10^{8}$ discrimination rate for unrelated individuals (Supporting Information Table 1). Alleles are referred to by their number of repeats determined using a reference panel of six cell lines of known genotype. Profiles were identical for all samples tested confirming that mlh1-3 and intracaecal tumours derived from HCT116. Yet, there were minor differences between the HCT116 and mlh1-3 profiles and the one available at the ATCC website. The first difference was located at the vWA marker and consisted of an addition of a single nucleotide that was detected in HCT116 and its mlh1-3 derived cell line, indicating that this mutation occurred in the HCT116 parental cell line before it was complemented with the MLH1-expressing vector; this observation was not unexpected since HCT116 is deficient in mismatch repair. The other difference is that the intensity of the Y-chromosome-specific amelogenin allele is below expected suggesting that part of the cells lost their Y-chromosome, or that a 6-bp deletion occurred in the Y-chromosome, generating a size that is identical to that of the $\mathrm{X}$-chromosome.

\section{Spontaneous evolution of the HCT116 and mlh1-3 intracaecal tumour xenografts}

As shown in Table 2 and Figure 3, the mean tumour volume in the group of mice implanted with mlh1-3-derived tumours was significantly smaller than in those with HCT116 $(P=.001)$, despite large variations within each group. Lymph node metastases and peritoneal carcinomatosis occurred significantly more often in the group of mice grafted with HCT116, compared to the group of mlh1-3 tumour-bearing animals $(P=.007$ and $P=.035$, respectively) (Table 2). Mice grafted with mlh1-3 tumours did not develop peritoneal carcinomatosis or liver metastasis; the only liver metastasis was observed in the group of mice grafted with the HCT116 tumour (Table 2). 


\section{Evolution of the HCT116 and mlh1-3 intracaecal tumour xenografts after surgical resection}

In order to study tumour evolution after curative surgery, HCT116 and mlh1-3 intracaecal tumour xenografts were resected at day 10. The rate of local recurrence after surgical resection did not differ significantly between the two groups, varying from $38 \%$ (5/13) for HCT116-R to $25 \%(3 / 12)$ for mlh1-3-R (Table 2); tumour volumes varied widely in both groups and were not significantly different. Lymph node metastases occurred only in the group of mice initially implanted with the HCT116 tumour, but the difference failed to reach the level of significance $(P=.096)$. Moreover, a single mouse of the mlh1-3 group displayed peritoneal carcinomatosis, whereas it occurred at a significantly higher frequency in mice initially grafted with the HCT116 tumour $(P=.011)$. No liver metastases were detected in either group. The rate of cure was significantly higher in the mlh1-3 group in which only $3 / 12$ animals relapsed, while $9 / 13$ animals of the HCT116 group relapsed $(P=.047)$ (Table 2).

\section{DISCUSSION}

CRCs are characterized by accumulation of genetic alterations that drive tumour progression from non-invasive adenomas to invasive adenocarcinomas. High-throughput arrays have been extensively used to uncover transcriptional gene expression or genomic aberration profiles in primary CRCs that might predict prognosis of patients with stage II ${ }^{43-45}$ and/or stage III ${ }^{46,47}$ CRC, or the site of metastases. ${ }^{48,49}$ Despite considerable efforts, no signature has been translated into the clinical management of patients due to low prediction accuracy. ${ }^{50}$

Patient-derived xenograft models have been developed to address specifically the role of putative oncogenes or tumour suppressor genes in CRC progression, or to predict drug sensitivity. ${ }^{51-55}$ For instance, orthotopic xenograft tumour models in immunodeficient mice have been successfully used to assess the function of TP53 and E-cadherin, ${ }^{39}$ and more 
recently that of TGF $\beta$ RII ${ }^{41}$ in $\mathrm{CRC}$ progression. Interestingly, intracaecal xenografted tumours may be subsequently resected, mimicking the surgical resection of primary CRC in humans, thus providing an opportunity to evaluate the benefit of surgery in well-defined tumour models.

Our orthotopic xenograft model recapitulates all aspects of human CRC progression, i.e. lymph node invasion, peritoneal carcinomatosis, liver metastasis and local recurrence after tumour surgery, with the exception of lung metastasis. Importantly, we were able to show that the MLH1 cDNA remained stably expressed throughout the experiments, even when selection pressure by hygromycin had been removed for in vivo experiments. All cell lines and tumours also shared the spectrum of mutations in the 26 mononucleotide coding repeats analysed and an identical profile at the 8 tetranucleotide STR loci, supporting that mlh1-3 is genetically close to the parental HCT116. In addition, all cell lines gave rise to tumours displaying similar morphological features. Thus, our model based on the isogenic HCT116 and mlh1-3 cell lines seems to be appropriate to investigate the impact of MLH1 expression on tumour progression independently of the MSI-driven mutations that previously arose in target genes.

We here show that the growth of tumours derived from the MLH1-complemented mlh1-3 cell line was slower compared to HCT116, a finding that is in keeping with the fact that MSI CRC tend to be larger than MSS CRC, possibly reflecting the role of MLH1 in cell cycle regulation and apoptosis. ${ }^{56}$ Interestingly, restoring MLH1 expression significantly decreased the rate of peritoneal carcinomatosis regardless of whether the tumour was resected or not. This is in line with a recent publication reporting that as many as $25 \%$ of the tumours arising in patients undergoing cytoreductive surgery for peritoneal carcinomatosis from CRC displayed MSI, a frequency that is higher than in unselected stage IV CRC, suggesting that MSI might favour peritoneal metastases. ${ }^{57}$ The decreased incidence of lymph node invasion was statistically significant when comparing mice that did not undergo surgery, but not for mice that underwent tumour resection, possibly due to lack of power since the number of mice was 
rather low. Yet, ethical considerations led us to reduce the number of animals used to achieve our aim, which was to document substantial differences in tumour progression.

MSI CRCs are considered to have a better prognosis compared to MSS CRCs, but the underlying molecular alterations have not been identified yet. ${ }^{58}$ In particular, the impact of MMR deficiency per se on tumour progression, independently of MSI-driven mutations, remained to be investigated. The possibility that mutations in TGFBR2, one of the genes most frequently mutated in MSI CRC, represent prognostic biomarkers has been investigated in several studies with conflicting results. ${ }^{59-61}$ Interestingly, a recent study reported that reexpressing TGFBR2 in the HCT116 cell line that carries a biallelic TGFBR2 frameshift mutation, increased cell survival and motility in vitro and enhanced their in vivo metastatic potential in an orthotopic model in nude mice, indicating that TGF $\beta$ signalling may indeed modulate the metastatic potential of MSI CRC. ${ }^{41}$ Experiments in which expression of wildtype $M L H 1$ is obtained by introducing a normal human chromosome 3 also provide a normal TGFBR2 allele, because the TGFBR2 gene is located in the close vicinity of MLH1 on chromosome 3, ${ }^{62}$ thus hampering the investigation of the respective contribution of MLH1 and TGFBR2 per se. The HCT116 / mlh1-3 model that we established overcomes this problem since MLH1 is restored by transfecting a vector expressing the wild-type MLH1 cDNA, which does not change the TGFBR2 status of HCT116 cells. ${ }^{42}$ Our results show that the clinical status of mice xenografted with the MLH1-expressing tumour was significantly improved compared to those with the parental HCT116-derived tumour, underlying the role of MLH1 deficiency in itself in tumour progression. Expression of MLH1 was notably associated with a significantly lower chance of recurrence after curative surgery, as well as a decreased incidence of lymph node invasion and peritoneal carcinomatosis in animals, regardless of whether the tumour was resected or left in situ.

In our xenograft experiments, the absence of MLH1 expression tended to be associated with a worse evolution, while patients with MSI CRC had a better stage-adjusted prognosis than those with CRC displaying chromosome instability. ${ }^{7,8}$ The major distinction between these apparently contradictory findings is that, in humans, the differences between MSI and non- 
MSI tumours reside not only in the fact that one of the MMR genes (most often MLH1 or $M S H 2$ ) is not functional, but also in the genome-wide accumulation of de novo mutations due to inefficient post-replicative repair, while in the animal model that we used, the only difference that we could detect was MLH1 expression. Although such animal models may help deciphering the impact of specific genetic alterations, such as MLH1 deficiency, on cancer progression, there are several limitations. Tumour xenograft models are not wellsuited to study interactions between cancer cells and tumour environment because interspecies molecular communications, including ligand-receptor interactions, are likely to differ. $^{54}$ In addition, being severely immuno-compromised, NOD/SCID mice obviate assessing the well-recognized role of the immune system, in the metastatic process in CRC. ${ }^{63}$ Addressing this question would be extremely hard as reconstitution of a human immune system in immunodeficient mice should be done with patient-matched immune cells, which greatly limits the feasibility.

\section{ACKNOWLEDGMENTS}

We thank Tatiana Ledent for her help in managing the animal house and Dr Erik Ruuth for critical reading of the manuscript.

\section{REFERENCES}

[1] Ferlay J, Soerjomataram I, Dikshit R, et al. Cancer incidence and mortality worldwide: sources, methods and major patterns in GLOBOCAN 2012. Int $J$ Cancer. 2015;136:E359-386.

[2] Pino MS, Chung DC. The chromosomal instability pathway in colon cancer. Gastroenterology. 2010;138:2059-2072. 
[3] Zaanan A, Meunier K, Sangar F, Flejou JF, Praz F. Microsatellite instability in colorectal cancer: from molecular oncogenic mechanisms to clinical implications. Cell Oncol (Dordr). 2011;34:155-176.

[4] Hughes LA, Khalid-de Bakker CA, Smits KM, et al. The CpG island methylator phenotype in colorectal cancer: progress and problems. Biochim Biophys Acta. 2012;1825:77-85

[5] Kane MF, Loda M, Gaida GM, et al. Methylation of the hMLH1 promoter correlates with lack of expression of $\mathrm{hMLH} 1$ in sporadic colon tumors and mismatch repairdefective human tumor cell lines. Cancer Res. 1997;57:808-811.

[6] Boland CR, Goel A. Microsatellite instability in colorectal cancer. Gastroenterology. 2010;138:2073-2087 e2073.

[7] Walther A, Johnstone E, Swanton C, Midgley R, Tomlinson I, Kerr D. Genetic prognostic and predictive markers in colorectal cancer. Nat Rev Cancer. 2009;9:489499.

[8] Roth AD, Delorenzi M, Tejpar S, et al. Integrated analysis of molecular and clinical prognostic factors in stage II/III colon cancer. J Natl Cancer Inst. 2012;104:16351646 .

[9] Fallik D, Borrini F, Boige V, et al. Microsatellite instability is a predictive factor of the tumor response to irinotecan in patients with advanced colorectal cancer. Cancer Res. 2003;63:5738-5744.

[10] Sinicrope FA, Sargent DJ. Clinical implications of microsatellite instability in sporadic colon cancers. Curr Opin Oncol. 2009;21:369-373.

[11] Hewish M, Lord CJ, Martin SA, Cunningham D, Ashworth A. Mismatch repair deficient colorectal cancer in the era of personalized treatment. Nat Rev Clin Oncol. 2010;7:197-208.

[12] Vilar E, Gruber SB. Microsatellite instability in colorectal cancer-the stable evidence. Nat Rev Clin Oncol. 2010;7:153-162. 
[13] Zaanan A, Cuilliere-Dartigues P, Guilloux A, et al. Impact of p53 expression and microsatellite instability on stage III colon cancer disease-free survival in patients treated by 5 -fluorouracil and leucovorin with or without oxaliplatin. Ann Oncol. $2010 ; 21: 772-780$

[14] Pritchard CC, Grady WM. Colorectal cancer molecular biology moves into clinical practice. Gut. 2011;60:116-129.

[15] Zaanan A, Flejou JF, Emile JF, et al. Defective mismatch repair status as a prognostic biomarker of disease-free survival in stage III colon cancer patients treated with adjuvant FOLFOX chemotherapy. Clin Cancer Res. 2011;17:7470-7478.

[16] Robinson BW, Im MM, Ljungman M, Praz F, Shewach DS. Enhanced radiosensitization with gemcitabine in mismatch repair-deficient HCT116 cells. Cancer Res. 2003;63:6935-6941.

[17] Le DT, Uram JN, Wang H, et al. PD-1 blockade in tumors with mismatch-repair deficiency. N Engl J Med. 2015;372:2509-2520.

[18] Dunne PD, McArt DG, O'Reilly PG, et al. Immune-derived PD-L1 gene expression defines a subgroup of stage II/III colorectal cancer patients with favorable prognosis who may be harmed by adjuvant chemotherapy. Cancer Immunol Res. 2016;4:582591.

[19] Calabrese P, Tsao JL, Yatabe $\mathrm{Y}$, et al. Colorectal pretumor progression before and after loss of DNA mismatch repair. Am J Pathol. 2004;164:1447-1453.

[20] Shibata D. When does MMR loss occur during HNPCC progression? Cancer Biomark. 2006;2:29-35.

[21] Loire E, Praz F, Higuet D, Netter P, Achaz G. Hypermutability of genes in Homo sapiens due to the hosting of long mono-SSR. Mol Biol Evol. 2009;26:111-121.

[22] Shah SN, Hile SE, Eckert KA. Defective mismatch repair, microsatellite mutation bias, and variability in clinical cancer phenotypes. Cancer research. 2010;70:431-435. 
[23] Miquel C, Jacob S, Grandjouan S, et al. Frequent alteration of DNA damage signalling and repair pathways in human colorectal cancers with microsatellite instability. Oncogene. 2007;26:5919-5926.

[24] Woerner SM, Yuan YP, Benner A, Korff S, von Knebel Doeberitz M, Bork P. SelTarbase, a database of human mononucleotide-microsatellite mutations and their potential impact to tumorigenesis and immunology. Nucleic Acids Res. 2010;38:D682-689.

[25] Gylfe AE, Kondelin J, Turunen M, et al. Identification of candidate oncogenes in human colorectal cancers with microsatellite instability. Gastroenterology. 2013;145:540-543 e522.

[26] Evans E, Alani E. Roles for mismatch repair factors in regulating genetic recombination. Mol Cell Biol. 2000;20:7839-7844.

[27] Harfe BD, Jinks-Robertson S. DNA mismatch repair and genetic instability. Annu Rev Genet. 2000;34:359-399.

[28] Hawn MT, Umar A, Carethers JM, et al. Evidence for a connection between the mismatch repair system and the G2 cell cycle checkpoint. Cancer Res. 1995;55:3721-3725.

[29] D'Atri S, Tentori L, Lacal PM, et al. Involvement of the mismatch repair system in temozolomide-induced apoptosis. Mol Pharmacol. 1998;54:334-341.

[30] Davis TW, Wilson-Van Patten C, Meyers M, et al. Defective expression of the DNA mismatch repair protein, MLH1, alters G2-M cell cycle checkpoint arrest following ionizing radiation. Cancer Res. 1998;58:767-778.

[31] Hickman MJ, Samson LD. Role of DNA mismatch repair and p53 in signaling induction of apoptosis by alkylating agents. Proc Natl Acad Sci $U S A$. 1999;96:10764-10769.

[32] Jones S, Chen WD, Parmigiani G, et al. Comparative lesion sequencing provides insights into tumor evolution. Proc Natl Acad Sci U S A. 2008;105:4283-4288. 
[33] Bresalier RS, Raper SE, Hujanen ES, Kim YS. A new animal model for human colon cancer metastasis. Int J Cancer. 1987;39:625-630.

[34] Fidler IJ. Orthotopic implantation of human colon carcinomas into nude mice provides a valuable model for the biology and therapy of metastasis. Cancer Metastasis Rev. 1991;10:229-243.

[35] Kuo TH, Kubota T, Watanabe M, et al. Early resection of primary orthotopicallygrowing human colon tumor in nude mouse prevents liver metastasis: further evidence for patient-like hematogenous metastatic route. Anticancer research. 1993;13:293-297.

[36] Pocard M, Tsukui H, Salmon RJ, Dutrillaux B, Poupon MF. Efficiency of orthotopic xenograft models for human colon cancers. In vivo. 1996;10:463-469.

[37] Bresalier RS, Hujanen ES, Raper SE, et al. An animal model for colon cancer metastasis: establishment and characterization of murine cell lines with enhanced liver-metastasizing ability. Cancer Res. 1987;47:1398-1406.

[38] Kubota T. Metastatic models of human cancer xenografted in the nude mouse: the importance of orthotopic transplantation. J Biol Chem. 1994;56:4-8.

[39] Pocard M, Debruyne P, Bras-Goncalves R, Mareel M, Dutrillaux B, Poupon MF. Single alteration of p53 or E-cadherin genes can alter the surgical resection benefit in an experimental model of colon cancer. Dis Colon Rectum. 2001;44:1106-1112.

[40] Flatmark K, Maelandsmo GM, Martinsen M, Rasmussen H, Fodstad O. Twelve colorectal cancer cell lines exhibit highly variable growth and metastatic capacities in an orthotopic model in nude mice. Eur J Cancer. 2004;40:1593-1598.

[41] Liu XQ, Rajput A, Geng L, Ongchin M, Chaudhuri A, Wang J. Restoration of transforming growth factor-beta receptor II expression in colon cancer cells with microsatellite instability increases metastatic potential in vivo. $J$ Biol Chem. 2011;286:16082-16090. 
[42] Jacob S, Aguado M, Fallik D, Praz F. The role of the DNA mismatch repair system in the cytotoxicity of the topoisomerase inhibitors camptothecin and etoposide to human colorectal cancer cells. Cancer Res. 2001;61:6555-6562.

[43] Agesen TH, Sveen A, Merok MA, et al. ColoGuideEx: a robust gene classifier specific for stage II colorectal cancer prognosis. Gut. 2012;61:1560-1567.

[44] Maak M, Simon I, Nitsche U, et al. Independent validation of a prognostic genomic signature (ColoPrint) for patients with stage II colon cancer. Ann Surg. 2013;257:1053-1058.

[45] Kopetz S, Tabernero J, Rosenberg R, et al. Genomic classifier ColoPrint predicts recurrence in stage II colorectal cancer patients more accurately than clinical factors. Oncologist. 2015;20:127-133.

[46] Salazar R, Roepman P, Capella G, et al. Gene expression signature to improve prognosis prediction of stage II and III colorectal cancer. J Clin Oncol. 2011;29:17-24.

[47] Wang L, Shen X, Wang Z, et al. A molecular signature for the prediction of recurrence in colorectal cancer. Mol Cancer. 2015;14:22.

[48] Bruin SC, Klijn C, Liefers GJ, et al. Specific genomic aberrations in primary colorectal cancer are associated with liver metastases. BMC cancer. 2010;10:662.

[49] Watanabe T, Kobunai T, Yamamoto $\mathrm{Y}$, et al. Prediction of liver metastasis after colorectal cancer using reverse transcription-polymerase chain reaction analysis of 10 genes. Eur J Cancer. 2010;46:2119-2126.

[50] Sanz-Pamplona R, Berenguer A, Cordero D, et al. Clinical value of prognosis gene expression signatures in colorectal cancer: a systematic review. PloS one. 2012;7:e48877.

[51] Dangles-Marie V, Pocard M, Richon S, et al. Establishment of human colon cancer cell lines from fresh tumors versus xenografts: comparison of success rate and cell line features. Cancer Res. 2007;67:398-407. 
[52] Bertotti A, Migliardi G, Galimi F, et al. A molecularly annotated platform of patientderived xenografts ("xenopatients") identifies HER2 as an effective therapeutic target in cetuximab-resistant colorectal cancer. Cancer Discov. 2011;1:508-523.

[53] Julien S, Merino-Trigo A, Lacroix L, et al. Characterization of a large panel of patientderived tumor xenografts representing the clinical heterogeneity of human colorectal cancer. Clin Cancer Res. 2012;18:5314-5328.

[54] Tentler JJ, Tan AC, Weekes CD, et al. Patient-derived tumour xenografts as models for oncology drug development. Nat Rev Clin Oncol. 2012;9:338-350.

[55] Nunes M, Vrignaud P, Vacher S, et al. Evaluating patient-derived colorectal cancer xenografts as preclinical models by comparison with patient clinical data. Cancer Res. 2015;75:1560-1566.

[56] O'Brien V, Brown R. Signalling cell cycle arrest and cell death through the MMR System. Carcinogenesis. 2006;27:682-692.

[57] Massalou D, Benizri E, Chevallier A, et al. Peritoneal carcinomatosis of colorectal cancer: novel clinical and molecular outcomes. Am J Surg. 2017;213:377-387.

[58] Popat S, Hubner R, Houlston RS. Systematic review of microsatellite instability and colorectal cancer prognosis. J Clin Oncol. 2005;23:609-618.

[59] Watanabe T, Wu TT, Catalano PJ, et al. Molecular predictors of survival after adjuvant chemotherapy for colon cancer. N Engl J Med. 2001;344:1196-1206.

[60] Kim GP, Colangelo LH, Wieand HS, et al. Prognostic and predictive roles of highdegree microsatellite instability in colon cancer: a National Cancer Institute-National Surgical Adjuvant Breast and Bowel Project Collaborative Study. J Clin Oncol. 2007;25:767-772.

[61] Shima K, Morikawa T, Yamauchi M, et al. TGFBR2 and BAX mononucleotide tract mutations, microsatellite instability, and prognosis in 1072 colorectal cancers. PloS one. $2011 ; 6: \mathrm{e} 25062$.

[62] Koi M, Umar A, Chauhan DP, et al. Human chromosome 3 corrects mismatch repair deficiency and microsatellite instability and reduces $\mathrm{N}$-methyl- $\mathrm{N}$ '-nitro- $\mathrm{N}$ - 
nitrosoguanidine tolerance in colon tumor cells with homozygous hMLH1 mutation. Cancer Res. 1994;54:4308-4312.

[63] Kirilovsky A, Marliot F, El Sissy C, Haicheur N, Galon J, Pages F. Rational bases for the use of the Immunoscore in routine clinical settings as a prognostic and predictive biomarker in cancer patients. Int Immunol. 2016;28:373-382. 


\section{FIGURES LEGENDS}

FIGURE 1. Examples of tumours and metastases obtained with the HCT116 cell line. Macroscopic examination and hematoxylin-eosin-safran stained slides of tumours developing in the caecum ( $A$ and $B$ ), lymph node ( $C$ and $D)$, liver ( $E$ and $F)$ and peritoneum ( $G$ and $H)$.

FIGURE 2. MLH1 expression and MSI phenotyping in HCT116 and mlh1-3 cell lines, and their derived xenografted tumours. MLH1 expression HCT116 and mlh1-3 cell lines was detected by Western blot (A) and compared to the MSS CRC HT29 cell line, used as a positive control; GAPDH was used as a loading control. MLH1 expression in HCT116 (B) and mlh1-3 (C) xenografted tumours was assessed by IHC; positive cells exhibit a strong nuclear staining. HE staining of small areas of these samples obtained at the same magnification is shown in inlays (B and $C$ ). Amplification profiles of three CAn dinucleotide polymorphic markers are shown for the HCT116 (D) and mlh1-3 (E) cell lines, and the mlh1-3-derived subcutaneous (sc) (F) and intracaecal (ic) (G) tumours. Multiplex PCR products corresponding to D5S107 (6-FAM-labelled, in blue), D18S1127 (NED-labeled, in black), and D17S1791 (NED-labeled, in black) co-migrated with the ROX-labelled $400 \mathrm{HD}$ size markers ranging from 50 to $400 \mathrm{bp}$ (in red), used to calculate the size of the PCR fragments. The $\mathrm{x}$ axis represents the size of the amplicons in bp; the amplicon sizes range from 133 to $155 \mathrm{pb}$ for D5S107, from 178 to $204 \mathrm{bp} D 18 S 1127$ and from 270 to $290 \mathrm{bp}$ for D17S1791. The chromatogram pattern obtained for HCT116 (D) shows additional peaks typical for MSI tumours, compared to MLH1-corrected mlh1-3 cell line (E); patterns obtained with subcutaneous $(F)$ and intracaecal $(G)$ tumours were identical to that of mlh1-3 cell line; samples are homozygous for D5S107 and heterozygous for D18S1127 and D17S1791 (parental alleles are indicated by arrows).

FIGURE 3. Growth of intracaecal HCT116 and mlh1-3 derived tumours. Volumes of intracaecal tumours derived from HCT116 (HCT116 a) and mlh1-3 (mlh1-3 •) when left in 
situ or of local recurrences arising after surgical resection (HCT116-R $\square$ and mlh1-3-R O) were measured at autopsy. Tumour volumes were compared using a one-tailed MannWhitney $U$ test. The difference was statistically significant for tumours left in situ $(P=.001)$, but not after surgical resection $(P=.125)$. 


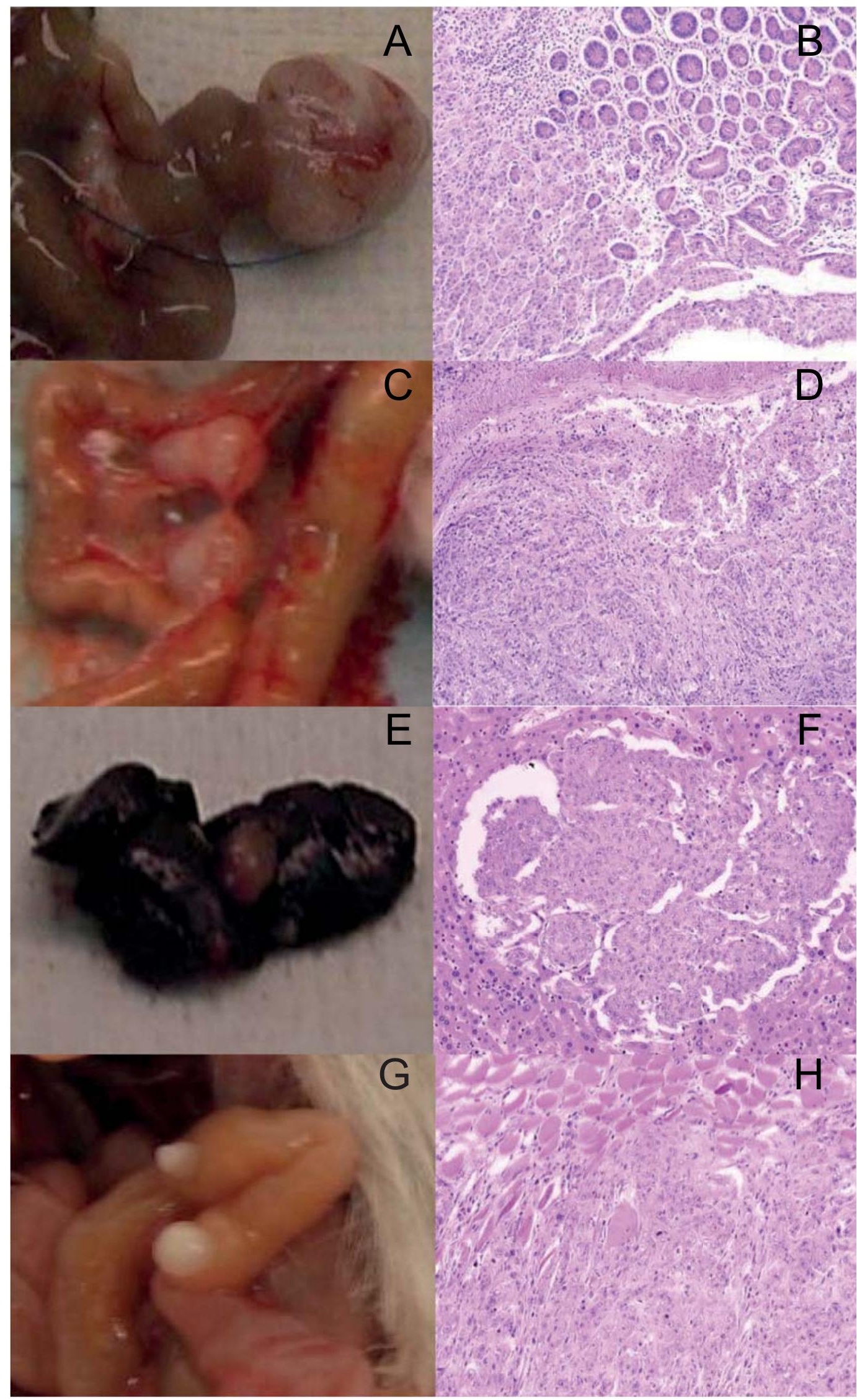






Meunier et al - Figure 2 


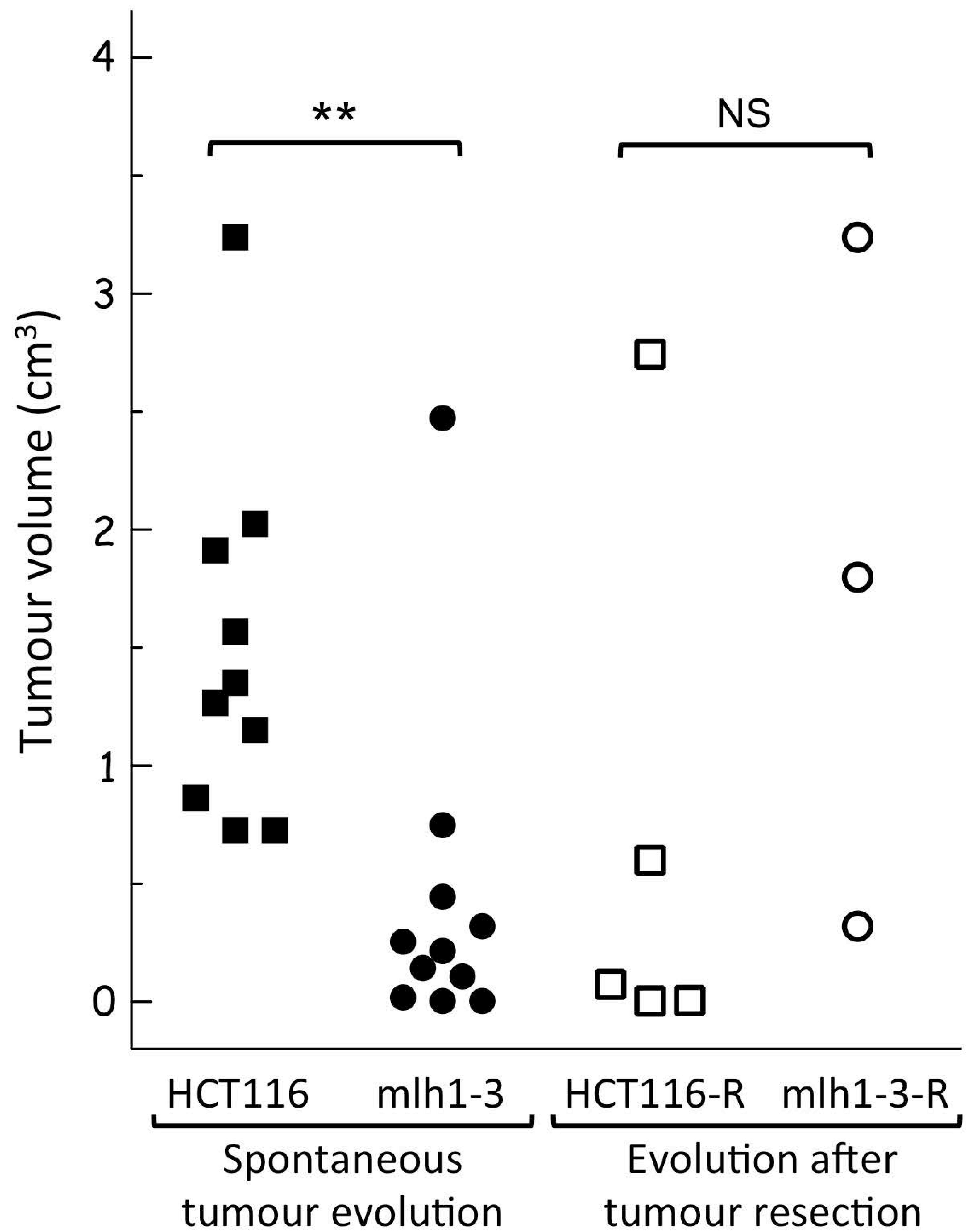

Meunier et al - Figure 3 
TABLE 1. Analysis of the mutation status of genes harbouring a mononucleotide repeat sequence in HCT116 and mlh1-3 cell lines

\begin{tabular}{|c|c|c|c|c|c|}
\hline Gene symbol & Gene ID & Repeat & Location & HCT116 & mlh1-3 \\
\hline ATR & 545 & A10 & $3 q 23$ & wt & wt \\
\hline$B A X$ & 581 & G8 & $19 q 13.3-q 13.4$ & $-1 / w t$ & $-1 / w t$ \\
\hline$B L M$ & 641 & A9 & $15 q 26.1$ & wt & wt \\
\hline BRCA1 & 672 & A8 & $17 q 21$ & wt & wt \\
\hline$C D C 25 C$ & 995 & A8 & $5 q 31$ & wt & wt \\
\hline CHEK1 & 1111 & A9 & 11q24-q24 & wt & wt \\
\hline ERCC5 & 2073 & A9 & $13 q 33$ & wt & wt \\
\hline LIG3 & 3980 & A8 & $17 q 11.2-q 12$ & wt & wt \\
\hline MBD4 & 8930 & A10 & $3 q 21-q 22$ & $-1 / w t$ & $-1 / w t$ \\
\hline MRE11A & 4361 & $\mathrm{~T} 11$ & $11 q 21$ & $-2 /-1$ & $-2 /-1$ \\
\hline MSH3 & 4437 & A8 & $5 q 11-q 12$ & -1 & -1 \\
\hline MSH6 & 2956 & $\mathrm{C} 8$ & $2 p 16$ & wt & wt \\
\hline POLA1 & 5422 & A8 & Xp22.1-p21.3 & wt & wt \\
\hline POLD3 & 10714 & A9 & $11 q 14$ & $-1 / w t$ & $-1 / w t$ \\
\hline$P R K D C$ & 5591 & A10 & $8 q 11$ & wt & wt \\
\hline RAD50 & 10111 & A9 & $5 q 31$ & $-1 / w t$ & $-1 / w t$ \\
\hline$R B B P 8$ & 5932 & A9 & $18 q 11.2$ & wt & wt \\
\hline RECQL & 5965 & A9 & $12 \mathrm{p} 12$ & $-1 / w t$ & $-1 / w t$ \\
\hline RIF1 & 55183 & A8 & $2 q 23.3$ & wt & wt \\
\hline$S M C 1 B$ & 27127 & A8 & 22q13.21 & wt & wt \\
\hline TCF7L2 & 6934 & A9 & $10 q 25.3$ & wt & wt \\
\hline TGFBR2 & 7048 & A10 & 3p22 & -1 & -1 \\
\hline ТОРВР1 & 11073 & A8 & $3 q 22.1$ & $-1 / w t$ & $-1 / w t$ \\
\hline TOPORS & 10210 & A8 & $9 p 21$ & $-1 / w t$ & $-1 / w t$ \\
\hline WRN & 7486 & A8 & 8p12-p11.2 & wt & wt \\
\hline XRCC2 & 7516 & T8 & $7 q 36.1$ & wt & wt \\
\hline
\end{tabular}

Gene symbols are according to HUGO gene nomenclature committee. Gene ID is from the NCBI Entrez gene database. The alleles detected were either wild-type (wt), or carry a $1 \mathrm{bp}$ or a 2 bp deletion (noted as "-1" or "-2", respectively); wt : only wild-type alleles were detected; -1/wt : both wt alleles and alleles carrying a 1 bp deletion were detected; -1 : only alleles with a 1 bp deletion were detected; -2/-1: alleles carrying a 2 bp deletion and alleles with a $1 \mathrm{bp}$ deletion were detected. All repeats are located in the coding sequences, except for MRE11A whose T11 repeat is located in an intron and whose shortening induces exon skipping; thus, a 1 or 2 bp deletion results in a frameshift mutation. 
TABLE 2. Clinical status of mice with intracaecal HCT116 and mlh1-3 tumour xenografts left in situ or after surgical resection

\begin{tabular}{|c|c|c|c|c|c|c|}
\hline & \multicolumn{3}{|c|}{$\begin{array}{l}\text { Spontaneous } \\
\text { tumour evolution }\end{array}$} & \multicolumn{3}{|c|}{$\begin{array}{l}\text { Evolution } \\
\text { after tumour resection }\end{array}$} \\
\hline & НСТ116 & mlh1-3 & $P$ & HCT116-R & mlh1-3-R & $P$ \\
\hline Number of mice & 10 & 11 & & 13 & 12 & \\
\hline \multicolumn{7}{|l|}{ Tumour volume $\left(\mathrm{mm}^{3}\right)$} \\
\hline Mean & 1483 & 431 & \multirow{2}{*}{.001} & 686 & 1787 & \multirow{2}{*}{.125} \\
\hline SEM & 242 & 215 & & 526 & 843 & \\
\hline Recurrence after surgery & & & & 9 & 3 & .047 \\
\hline Local recurrence after surgery & & & & 5 & 3 & .673 \\
\hline Distant recurrence & 7 & 1 & .007 & 8 & 1 & .011 \\
\hline Lymph node metastases & 7 & 1 & .007 & 4 & 0 & .096 \\
\hline Liver metastases & 1 & 0 & .476 & 0 & 0 & $\mathrm{na}^{\mathrm{a}}$ \\
\hline Peritoneal carcinomatosis & 4 & 0 & .035 & 8 & 1 & .011 \\
\hline
\end{tabular}

Fifteen mice were initially grafted in each group; the number of mice analysed decreased due to early death after tumour graft $(n=3)$ or surgical resection $(n=5)$, and to the absence of tumour take $(n=6)$. The volumes of tumours growing on the caecum were compared using a one-tailed Mann-Whitney $U$ test. To compare the number of mice with recurrence, lymph node metastases, peritoneal carcinomatosis and liver metastases, $P$ values were calculated using two-sided Fisher's exact tests.

${ }^{a}$ not analyzed (na): no $P$ value could be calculated to compare the number of mice with liver metastases after tumour resection since there was no event in either group. 
Supporting Information Table 1. DNA fingerprinting of HCT116 and mlh1-3 cell lines and their derived intracaecal tumours

\begin{tabular}{llccccccccc}
\hline & D5S818 & D7S820 & D13S317 & D16S539 & Amelogenin & CSF1PO & THO1 & TPOX & vWA \\
\hline HCT116 & ATCC & $\mathbf{1 0 , 1 1}$ & $\mathbf{1 1 , 1 2}$ & $\mathbf{1 0 , 1 2}$ & $\mathbf{1 1 , 1 3}$ & $\mathbf{X , Y}$ & $\mathbf{7 , 1 0}$ & $\mathbf{8 , 9}$ & $\mathbf{8 , 9}$ & $\mathbf{1 7 , 2 2}$ \\
HCT116 & In vitro cell line & 10,11 & 11,12 & 10,12 & 11,13 & $\mathrm{X}(\mathrm{Y})$ & 7,10 & 8,9 & 8,9 & $17,22.1$ \\
& Caecum graft, P5 & 10,11 & 11,12 & 10,12 & 11,13 & $\mathrm{X}$ & 7,10 & 8,9 & 8,9 & $17,22.1$ \\
\multirow{2}{*}{ mIh1-3 } & In vitro cell line & 10,11 & 11,12 & 10,12 & 11,13 & $\mathrm{X}$ & 7,10 & 8,9 & 8,9 & $17,22.1$ \\
& Caecum graft, P6 & 10,11 & 11,12 & 10,12 & 11,13 & $\mathrm{X}$ & 7,10 & 8,9 & 8,9 & $17,22.1$ \\
& & & & & & & & & &
\end{tabular}

Profiling was performed using the eight short tandem repeat (STR) markers recommended by the American Type Cell Culture (ATCC), which enables a 1 in $10^{8}$ discrimination rate for unrelated individuals. Multiplex PCR was carried and analyzed as in Figure 2D-G. Alleles are referred to by their number of repeats defined using a panel of six cell lines used as reference. The $\mathrm{Y}$ chromosome specific amelogenin allele shown in parentheses indicate that its intensity is far below expected. The size of the vWA 22.1 allele is $1 \mathrm{bp}$ longer than the allele with 22 repeats reported for the HCT116 cell line on the ATCC website. 